\title{
Epidural Fibrosis after Lumbar Disc Surgery: Prevention and Outcome Evaluation
}

\author{
Mohamed M. Mohi Eldin ${ }^{1}$, Naglaa M. Abdel Razek ${ }^{2}$ \\ ${ }^{1}$ Department of Neurosurgery, Faculty of Medicine, Cairo University, Cairo, Egypt \\ ${ }^{2}$ Department of Radiodiagnosis, Faculty of Medicine, Cairo University, Cairo, Egypt
}

Study Design: This is a prospective, randomized, controlled study designed and conducted over 10 years from 2002 to 2012.

Purpose: The study aimed to monitor the effect of suction drains (SD) on the incidence of epidural fibrosis (EF) and to test, if the use of SD alone, SD with local steroids application, SD combined with fat grafts and local steroids application, or SD combined with fat grafts and without local steroids application, would improve outcome.

Overview of Literature: EF contributes to significant unsatisfactory failed-back syndrome. Efforts have been tried to reduce postoperative EF, but none were ideal.

Methods: Between September 2002 and 2012, 290 patients with symptomatic unilateral or bilateral, single-level lumbar disc herniation were included in the study. Two groups were included, with 165 patients in group I (intervention group) and 125 patients in group II (control group). Group I was subdivided into four subgroups: group la (SD alone), group lb (SD+fat graft), group Ic (SD+local steroids), and group Id (SD+fat graft+local steroids).

Results: The use of SD alone or combined with only fat grafts, fats grafts and local steroids application, or only local steroids application significantly improved patient outcome and significantly reduced EF as measured by magnetic resonance imaging (MRI).

Conclusions: This study has clearly demonstrated the fact that the use of suction drainage alone or combined with only fat grafts, fats grafts and local steroids application, or only local steroids application significantly improved patient outcome with respect to pain relief and functional outcome and significantly reduced EF as measured by an MRI. A simple grading system of EF on MRI was described.

Keywords: Epidural fibrosis; Suction drain; Lumbar; Failed back; Prevention

\section{Introduction}

Epidural fibrosis (EF) is a natural consequence of lumbar disc surgery. However, it contributes to significant unsatisfactory relief of symptoms and failed-back syndrome (FBS). EF, by tethering the dura matter, can adversely affect the outcome and make the nerve roots vulnerable to injury, with dural tears occurring during a reoperation along with an increased incidence of arachnoiditis. EF around the nerve root can be more refractory to treatment than the original disc herniation itself. This is in addition to the fact that a reoperation on the scar can produce more scarring $[1,2]$.

There is no absolutely effective technique that we currently have to reduce EF formation after lumbar disc surgery. Many considerable efforts have been tried to reduce

Received Nov 4, 2014; Accepted Nov 25, 2014

Corresponding author: Mohamed M. Mohi Eldin

Department of Neurosurgery, Faculty of Medicine, Cairo University, Egypt

Tel: +20-233022907, Fax: +20-233022907, E-mail: mmohi63@yahoo.com 
postoperative EF, but none have been found to be ideal. EF still forms even in minimally invasive interventions [3]. Theoretically speaking, decreasing the amount of postoperative hematoma and, hence, its transformation into fibrous tissue, are the main targets to minimize the risk of EF. So, suction drains (SD) used for removal of collections at the operation site may have an important role in this aspect. Other theoretical approaches include providing a barrier between the exposed dura and the healing tissues. Autogenous barriers are practically the best available. Free fat grafting is recognized by some to be the standard treatment for prevention of postoperative EF [4-6]. Lastly, applying a drug locally, which is supposed to decrease scar tissue formation, may be accepted, provided that it will not add any harm to the patient $[7,8]$. The questions of whether SD, epidural fat placement, and local steroids application reduce $\mathrm{EF}$ and whether the reduction of $\mathrm{EF}$ improves outcomes have not been answered.

\section{Study objective}

In a trial to determine the effects of these theoretical approaches on the amount of EF formed and on patient outcome, this prospective, randomized, controlled study was designed and conducted over 10 years from 2002 to 2012. This study had several objectives; to monitor the effect of SD on the incidence of postoperative EF and to test if the use of SD alone or combined with only fat grafts, fats grafts and local steroids application, or only local steroids application would improve patient outcome.

\section{Materials and Methods}

\section{Patient population}

Between September 2002 and September 2012, a total of 290 patients (125 women, 165 men) previously un-operated and indicated for surgery, with a symptomatic unilateral or bilateral, single-level (L4, 5 or L5, S1) lumbar disc herniation, were included in the present study. Patients enrolled in the study were patients of Cairo university hospitals and Naser Institute Hospital in Cairo. Patients between 20 years and 60 years of age were included in the study. Criteria for lack of significant response to conservative treatment, and, hence, indication for surgery were persistent or recurrent pain, despite a satisfactory duration of more than 3 months of using anti-inflammatory and muscle relaxant drugs combined with pain killers, absolute bed rest, and salt restriction.

Patient with cauda equina syndrome, multilevel affection, symptomatic lumbar canal stenosis, lumbar instability or deformity, previous epidural or intradural injection of drugs or contrast media, and severe medical illnesses, including active infection, were excluded from the study. Other chronic conditions that interfered with clinical or radiological assessments, such as hip diseases, were also excluded.

\section{Study design}

The present study is a prospective, randomized, controlled study conducted and designed to evaluate the clinical outcome of SD alone and combined with local application of fat grafts and/or steroids in prevention of post-lumbar discectomy EF. The outcomes were compared with outcomes in patients in whom neither the drain nor the barrier or steroids was implanted.

The clinical design included simple randomization of the subjects into one of two groups, with 165 patients in group I (intervention group) and 125 patients in group II (control group). Group II served as control, with only the surgical procedure done without SD, local fat grafts, or steroids application. Group I underwent decompressive surgery of their symptomatic nerve root, followed by $\mathrm{SD}$ alone or combined with local fat graft and/or steroid application. Group I was subdivided into 4 subgroups: group Ia (SD alone) 45 patients, group Ib (SD+fat graft) 40 patients, group Ic (SD+local steroids) 40 patients, and group Id (SD+fat graft+local steroids) 40 patients.

The groups and subgroups were similar with respect to age, distribution of radicular pain, low back pain, and similar activity-related pains and had near straight leg raise (SLR) preoperatively. The patients received similar medications preoperatively. Although we tried to have the same number of patients in both groups, patients who were lost to follow up were excluded from the study. Operative and discharge information were obtained from the groups regarding the surgery and the condition of the patient at hospital discharge.

\section{Procedure}

All patients in both groups were provided identical preparation and intervention. All patients were operated in a 
prone position, through single-level midline procedure (limited to L4, 5, or L5, S1 levels), in which a decompression interlaminar, micro-, hemi-, or formal laminectomy and discectomy technique was performed exposing the nerve root and dural sac. Maximum hemostasis was the target in all cases, and our protocol limited the use of any hemostatic materials. In all group I cases a SD with sideholes was placed at the operation site with mild negativepressure. Then, either the fat grafts and/or local steroids ( $2 \mathrm{~mL}$ of Diprofos Suspension containing betamethasone dipropionate equivalent to $10 \mathrm{mg}$ betamethasone and betamethasone sodium phosphate equivalent to $4 \mathrm{mg}$ betamethasone) were then placed over the exposed dura, according to the patient subgroup. The patient was mobilized the night of surgery. The drains were maintained for 24-36 hours postoperatively. After the drain was removed, total drainage was noted.

\section{Evaluation and outcomes assessment}

In addition to the standard study protocol evaluation, patients were evaluated for intraoperative and postoperative complications.

\section{1) Clinical outcome assessment}

At each visit, a clinical evaluation and neurological assessment for strength, reflexes, sensation, and pain related to the operated level were recorded. We evaluated activityrelated pain, low back and radicular pain, range of motion, and SLR examinations. Pain intensity, assessed both pre- and postoperatively, was evaluated by the numeric verbal rating (NVR) scale. The patient was asked to mark where the pain intensity fell along the continuum, marking his pain into number form, with 0 meaning no pain while 10 meaning worst possible pain. Then, according to the results of NVR scale, patients were categorized into 4 categories: pain free (0), improved pain (1-4), fair (5-7), and bad (8-10) categories. Significant relief was defined as pain relief of $50 \%$ or greater; otherwise, it was nonsignificant (less than 50\%). Significant pain relief included patients in the pain free and improved pain categories while non-significant pain relief included patients in the fair and bad categories. Duration of pain relief was judged to be short-term, if relief was less than 6 months. If relief lasted for at least 6 months and up to 3 years, it was considered long-term.

Success was defined as all of the following: (1) no or minimal remaining pain, (2) work not adversely affected, (3) no use of analgesic medications, and (4) patient satisfaction with the procedure.

The patients' functional clinical outcome was measured according to the recovery and clinical improvements in SLR test and in range of motion test, including flexion $\left(\right.$ normal $60^{\circ}$ ), extension (normal $25^{\circ}$ ), and lateral flexion (normal $25^{\circ}$ ).

\section{2) Radiologic evaluation assessment}

We used magnetic resonance imaging (MRI)-based evaluation for the extent of EF. This was done at one-year follow up. MR examinations followed a standard protocol. Axial images covered at least one level above the operative site to one level below the site (except for L5-S1, where the caudal most slices was to the mid S1body). Categorization of epidural granulation or scar tissue was done for three cuts per disc level, four quadrants per level, with the main assessment at the level passing through the neural exit foramina.

Criteria for EF identification included iso- to hypointense signal relative to inter-vertebral discs on T1-weighted MR images, replacing the epidural fat signal intensity. $\mathrm{EF}$ was fairly homogeneous. Both $\mathrm{EF}$ and disc protrusions may show mass effect, especially in early stages of granulation tissue formation. Aging of the EF may result in retraction of the dural towards the side of the scar. EF was enhanced immediately after the injection of gadolinium, in contrast to recurrent herniation, which may need up to twenty minutes after contrast injection.

EF Grading: the amount of EF was graded on a scale of $0-4$ for each quadrant at each imaging slice encompassing the operative level: $0=$ no to trace scar; $1,2,3,4=$ more than trace to $25 \%, 50 \%, 75 \%$, and $100 \%$, respectively. If the patient had a scar score 4 in any one of the quadrants, it was defined as an extensive scar. The whole case was described as having none, mild, moderate, or extensive EF. Fig. 1 shows axial T1-weighted images that show right posterior grade 2 at 12 months. The right anterior epidural space was grade 4 .

\section{Results}

There were no clinically significant differences between the groups as measured by neurological tests, occurrence, and clinical signs and symptoms of adverse events or wound healing characteristics. Patients were nearly 


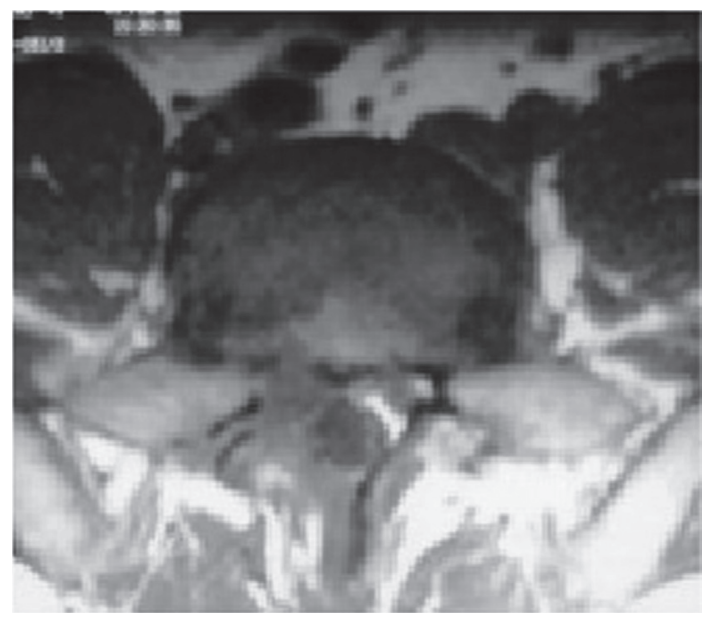

Fig. 1. Axial T1-weighted images show right posterior grade 2 at 12 months. The right anterior epidural space was grade 4 .

equally distributed among both groups (57\% of the patients are in group I, and $43 \%$ are in group II). Demographic factors, such as age, sex, and side of surgery, did not differ significantly between patients with discrete subgroups (Table 1).

Surgical approach was performed at the levels L4-5 $(\mathrm{n}=155)$ and L5-S1 $(\mathrm{n}=135)$. No complication was reported, and no new neurological deficits occurred. Neither periprocedural surgical complications, wound infection, nor discitis was observed in our patient groups. No adverse events were directly attributable to SD, fat grafts, or steroid local application. Mean length of hospital stay was 3 days. In group I, mean amount of drainage was $35.00 \pm 10.0 \mathrm{~mL}$.
In the following sections, the outcome of the statistical analysis concerning sort-term and late pain relief, functional outcome, SLR test, and MRI findings will be discussed in details.

\section{First: sort-term and late pain outcome analysis}

Comparing both groups with respect to short-term and late pain relief, we found that a higher proportion of patients in group I showed pain relief compared to the control group, as well as compared to the baseline findings (Table 2, Fig. 2).

Significant pain relief ( $>50 \%)$ was calculated for both groups. The short-term pain relief outcome, which was assessed 6 months after the operation, indicated a success rate (significant pain relief) $97 \%$ in the treatment group, as compared to $68 \%$ in the control group. However, late follow-up, which was assessed 12 months after the operation, indicated a success rate of $81.8 \%$ in the treatment group, as compared to $60 \%$ in the control group (Table 3 , Fig. 3).

On the other hand, failure rate (non-significant pain relief) was slightly elevated from $3 \%$ at 6 months to $18.2 \%$ at 12 months in the treatment group, as compared to moderate elevation from $32 \%$ at 6 months to $40 \%$ at 12 months in the control group, with a special attention that no one in the treatment group experienced the bad category of pain. Significant pain relief was also longer in the treatment group. Duration of significant relief $(>50 \%)$ that was 9.3+3.6 months in patients was considered as successful.

In order to test the statistical significance of the difference in proportions of patients regarding pain relief

Table 1. Demographic and procedural characteristics

\begin{tabular}{|c|c|c|c|c|c|c|}
\hline \multirow{2}{*}{ Characteristic } & \multicolumn{5}{|c|}{ Group I (treatment group) } & \multirow{2}{*}{$\begin{array}{c}\text { Group II } \\
\text { (control group }\end{array}$} \\
\hline & $1 \mathrm{~A}$ & 1B & $1 \mathrm{C}$ & $1 \mathrm{D}$ & Total & \\
\hline No. of patients (\%) & $45(27.4)$ & $40(24.2)$ & $40(24.2)$ & $40(24.2)$ & $165(100)$ & $125(100)$ \\
\hline Age (yr) (mean) & 38 & 42 & 36 & 40 & & 38 \\
\hline \multicolumn{7}{|l|}{ Gender } \\
\hline Male & 20 & 25 & 30 & 15 & 90 & 75 \\
\hline Female & 25 & 15 & 10 & 25 & 75 & 50 \\
\hline Weight (kg) (mean) & 75 & 85 & 80 & 78 & 79.5 & 80 \\
\hline Procedure & SD & SD+fat & SD+steroids & SD+fat+steroids & & \\
\hline
\end{tabular}

SD, suction drains. 
Table 2. Short-term and late pain outcome analysis

\begin{tabular}{|c|c|c|c|c|c|c|}
\hline \multirow{2}{*}{ Pain relief } & \multicolumn{5}{|c|}{ Group I (treatment group) } & \multirow{2}{*}{$\begin{array}{l}\text { Group II } \\
\text { (control) }\end{array}$} \\
\hline & $1 \mathrm{~A}$ & $1 \mathrm{~B}$ & $1 \mathrm{C}$ & $1 \mathrm{D}$ & Total & \\
\hline \multicolumn{7}{|l|}{$6 \mathrm{mo}$} \\
\hline Pain free ${ }^{a)}$ & $30(66.7)$ & $35(87.5)$ & $30(75)$ & $40(100)$ & 135 (81.8) & $70(56)$ \\
\hline Improved ${ }^{\text {a) }}$ & $10(22.2)$ & $5(12.5)$ & $10(25)$ & 0 & $25(15.2)$ & $15(12)$ \\
\hline Fair $^{\text {a) }}$ & $5(11.1)$ & 0 & 0 & 0 & $5(3)$ & $15(12)$ \\
\hline $\mathrm{Bad}^{\mathrm{al}}$ & 0 & 0 & 0 & 0 & 0 & $25(20)$ \\
\hline \multicolumn{7}{|l|}{$1-3 \mathrm{yr}$} \\
\hline Pain free ${ }^{a)}$ & 25 (55.6) & $30(75)$ & $20(50)$ & $30(75)$ & 105 (63.6) & $60(48)$ \\
\hline Improved ${ }^{\text {a) }}$ & $10(22.2)$ & $5(12.5)$ & $10(25)$ & $5(12.5)$ & $30(18.2)$ & $15(12)$ \\
\hline Fair $^{\text {a) }}$ & $10(22.2)$ & $5(12.5)$ & $10(25)$ & $5(12.5)$ & $30(18.2)$ & $20(16)$ \\
\hline $\mathrm{Bad}^{\mathrm{a})}$ & 0 & 0 & 0 & 0 & 0 & $30(24)$ \\
\hline
\end{tabular}

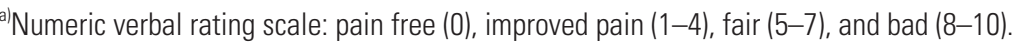

Short-term pain relief (6 mo) - group I

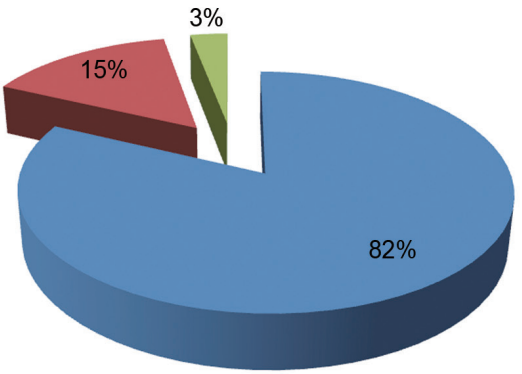

Late pain relief (1-3 yr) - group I

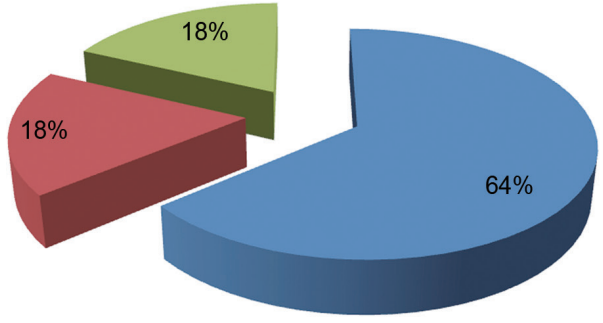

Short-term pain relief (6 mo) - group II

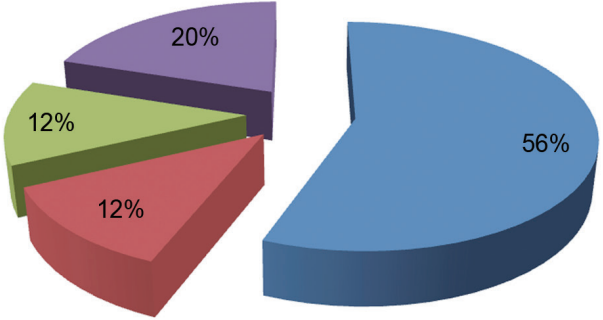

Late pain relief (1-3 yr) - group II

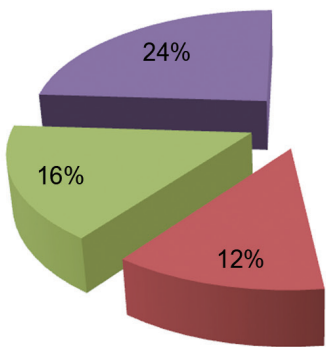

Pain free

Improved

Fair

Bad

Fig. 2. Short-term and late pain relief in both groups.

among both groups, Pearson chi-square, likelihood ratio, and Fisher exact tests were performed for both short-term and late time. The results, as shown in Table 4, showed statistically significant difference between both groups.

The same tests were performed to evaluate the difference in pain relief among the four sub-groups of group I. The results, as shown in Table 5 , showed only statistically significant difference in short-term pain relief between the four sub-groups. However, the difference in late pain relief between the four sub-groups proved to be statistically insignificant. This meant that, in the long term (1-3 years), there was no significant difference in pain relief between the four methods.

To sum up the first results, namely, sort-term and late 
Table 3. Short-term and late significant pain relief in both groups

\begin{tabular}{|c|c|c|c|c|c|c|}
\hline \multirow{2}{*}{ Pain relief } & \multicolumn{4}{|c|}{ Group I (treatment group) } & & \multirow{2}{*}{$\begin{array}{l}\text { Group II } \\
\text { (control) }\end{array}$} \\
\hline & $1 \mathrm{~A}$ & $1 \mathrm{~B}$ & $1 \mathrm{C}$ & $1 \mathrm{D}$ & Total & \\
\hline \multicolumn{7}{|l|}{$6 \mathrm{mo}$} \\
\hline Significant (\%) & 88.90 & 100 & 100 & 100 & 97.00 & 68 \\
\hline Insignificant (\%) & 11.10 & 0 & 0 & 0 & 3.00 & 32 \\
\hline \multicolumn{7}{|l|}{$1-3 y r$} \\
\hline Significant (\%) & 77.80 & 87.50 & 75.00 & 87.50 & 81.80 & 60.00 \\
\hline Insignificant (\%) & 22.20 & 12.50 & 25.00 & 12.50 & 18.20 & 40.00 \\
\hline
\end{tabular}

Short-term significant pain relief (6 mo) - group I

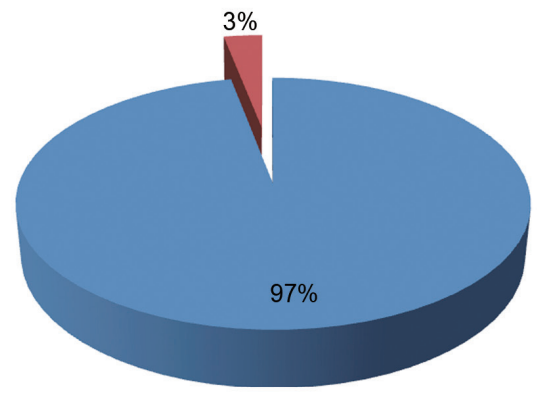

Late significant pain relief (1-3 yr) - group I

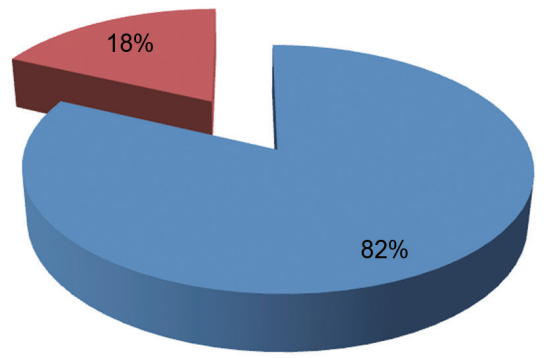

Short-term significant pain relief $(6 \mathrm{mo})$ - group II

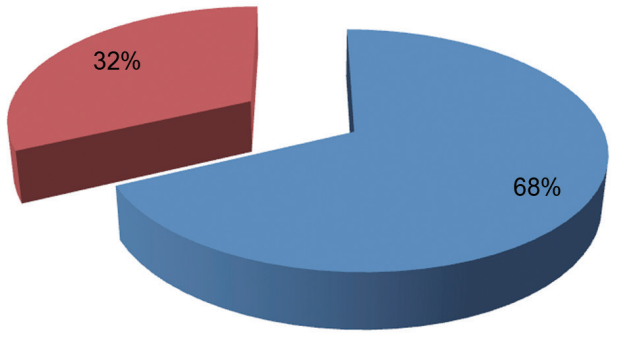

Significant

Insignificant

Late significant pain relief (1-3 yr) - group II

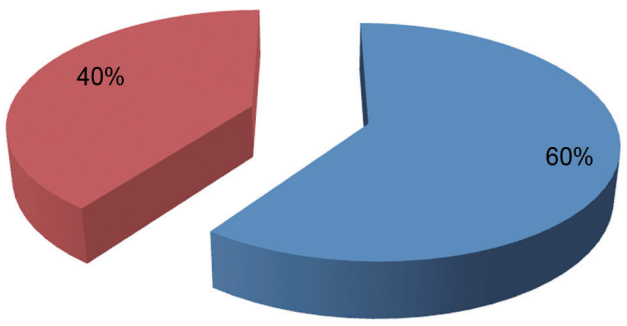

Fig. 3. Short-term and late significant pain relief in both groups.

Table 4. Statistical significance tests of difference in pain relief among both groups

\begin{tabular}{lccc} 
Test name & Value & Asymptotic significance (2-sided) & Exact significance (2-sided) \\
Short-term (6 mo) & & 0 & 0 \\
\hline Pearson chi-square & 48.516 & 0 & 0 \\
\hline Likelihood ratio & 57.851 & & 0 \\
\hline Fisher exact test & 53.85 & 0 & 0 \\
\hline Late (1-3 yr) & & 0 & 0 \\
\hline Pearson chi-square & 44.604 & & 0 \\
\hline Likelihood ratio & 55.594 & & 0 \\
\hline Fisher exact test & 51.607 & & \\
\hline
\end{tabular}


Table 5. Statistical significance tests of difference in pain relief among 4 sub-groups of group I

\begin{tabular}{|c|c|c|c|}
\hline Test name & Value & Asymptotic significance (2-sided) & Exact significance (2-sided) \\
\hline \multicolumn{4}{|l|}{ Short-term (6 mo) } \\
\hline Pearson chi-square & 26.889 & 0 & 0 \\
\hline Likelihood ratio & 31.990 & 0 & 0 \\
\hline Fisher exact test & 24.289 & & 0 \\
\hline \multicolumn{4}{|l|}{ Late $(1-3 \mathrm{yr})$} \\
\hline Pearson chi-square & 8.948 & 0.177 & 0.178 \\
\hline Likelihood ratio & 9.057 & 0.170 & 0.187 \\
\hline Fisher exact test & 8.746 & & 0.183 \\
\hline
\end{tabular}

pain outcome analysis:

Conclusion (1): The results of short-term and late pain relief throughout the study were best in group $1 \mathrm{D}$, followed by group $1 \mathrm{~B}$, group $1 \mathrm{C}$, and group $1 \mathrm{~A}$, respectively. The worst results were obtained in the group 2 .

Conclusion (2): There was a statistically significant difference in short-term and late pain relief between the Intervention group and control group.

Conclusion (3): There was no statistically significant difference between four subgroups of Intervention group except in the short-term (within 6 months from the surgery). However, in the long run (1-3 years from the surgery), there was a statistical difference with respect to pain relief. Therefore, it could be concluded that: In the long run, using suction drainage with a combination of fat grafts and steroid local application significantly increased pain relief.

\section{Second: functional outcome analysis}

Analysis of functional outcome showed significant improvements in the intervention group compared to the baseline, as well as the control group, at intervals of 3 months, 6 months, and 12 months (Table 6, Fig. 4).

Assessing functional outcome, significant differences were determined between preoperative (baseline) values and postoperative values in the whole study group. The early functional outcome in the control group, assessed 3 months after the operation showed the best achieved results, with gradual decrease in short-term (6 months) followed by more decrease in late follow-up. On the contrary, there was a trend toward better outcome at 1 year in the treatment group. Based on the definition that less than 6 months of relief was considered short-term and longer than 6 months of relief was considered long-term, a significant number of patients obtained long-term relief with improvement in pain and functional status in the treatment group.

To sum up the second results, namely, functional outcome analysis:

Conclusion (4): The functional outcome analysis, with respect to flexion, extension, lateral flexion, and SLR, showed the best results in group $1 \mathrm{D}$, followed by group $1 \mathrm{~B}$, group $1 \mathrm{C}$, and group $1 \mathrm{~A}$ respectively. The worst results were obtained in group 2 . Therefore, it could be concluded that: In the long run, using suction drainage with a combination of fat grafts and steroid local application significantly enhanced the functional outcome measured by flexion, extension and lateral flexion angles.

\section{Third: SLR test analysis}

Results showed improvement in straight leg raising following surgery. Based on their SLR testing, patients were classified into three categories: (1) patients who got better, (2) patients who stayed the same, and (3) patients who got worse. Table 7 shows the numbers and percentages of patients in each category for each group (and sub-group) along three time periods: 6 months, 12 months, and 3 years.

There was a significant difference in the percentage of patients who got better between intervention group 1 and control group 2 (Fig. 5). It could also be noticed that the percentage of patients who got worse in the control group increased with time while no patients got worse at all in the intervention group, even in a period of 3 years. 
Table 6. Functional outcome analysis for both groups

\begin{tabular}{|c|c|c|c|c|}
\hline \multirow[b]{2}{*}{ Outcome } & \multicolumn{3}{|c|}{ Range of motion } & \multirow{2}{*}{$\begin{array}{l}\text { Straight leg raise test } \\
\left.\text { (normal } 90^{\circ}\right)\end{array}$} \\
\hline & $\begin{array}{c}\text { Flexion } \\
\left.\text { (normal } 60^{\circ}\right)\end{array}$ & $\begin{array}{l}\text { Extension } \\
\left(\text { normal } 25^{\circ}\right)\end{array}$ & $\begin{array}{l}\text { Lateral flexion } \\
\left(\text { normal } 25^{\circ}\right)\end{array}$ & \\
\hline
\end{tabular}

Group 1A

\begin{tabular}{|lllll|}
\hline Baseline & 25 & 10 & 8 & 40 \\
\hline $6 \mathrm{mo}$ & 40 & 15 & 15 & 70 \\
\hline $12 \mathrm{mo}$ & 40 & 18 & 15 & 80 \\
\hline $3 \mathrm{yr}$ & 45 & 18 & 15 & 85 \\
\hline Group 1B & & & 8 & 40 \\
\hline Baseline & 25 & 10 & 18 & 85 \\
\hline $6 \mathrm{mo}$ & 45 & 18 & 18 & 85 \\
\hline $12 \mathrm{mo}$ & 45 & 20 & 20 & 90 \\
\hline $3 \mathrm{yr}$ & 50 & 22 & & \\
\hline
\end{tabular}

Group 1C

\begin{tabular}{|lllll}
\hline Baseline & 25 & 10 & 8 & 40 \\
\hline 6 mo & 45 & 17 & 16 & 75 \\
$12 \mathrm{mo}$ & 45 & 17 & 16 & 80 \\
\hline $3 \mathrm{yr}$ & 55 & 20 & 18 & 85 \\
\hline
\end{tabular}

Group 1D

\begin{tabular}{|ccccc} 
Baseline & 25 & 10 & 8 & 40 \\
$6 \mathrm{mo}$ & 50 & 20 & 18 & 90 \\
\hline $12 \mathrm{mo}$ & 55 & 25 & 22 & 90 \\
\hline $3 \mathrm{yr}$ & 60 & 25 & 25 & 90 \\
\hline
\end{tabular}

Group 2 (control)

\begin{tabular}{lrrrr} 
Baseline & 25 & 10 & 8 & 40 \\
$6 \mathrm{mo}$ & 35 & 14 & 12 & 70 \\
$12 \mathrm{mo}$ & 30 & 15 & 12 & 60 \\
$3 \mathrm{yr}$ & 30 & 15 & 10 & 60 \\
\hline
\end{tabular}

Fig. 6 shows that $100 \%$ of patients in group $1 D$ (SD+fat graft+local steroids) got better starting from 3 months, and they also were still better even in the long run (up to 3 years). Group 1D showed the best results, followed by group $1 \mathrm{~B}$, then $1 \mathrm{C}$, then $1 \mathrm{~A}$. The worst results were shown in patients in group 2.

Conclusion (5): SLR test analysis showed the best results in group $1 \mathrm{D}$, followed by group $1 \mathrm{~B}$, group $1 \mathrm{C}$, and group 1A respectively. The worst results were obtained in the group 2. Therefore, it could be concluded that: Using suction drainage with a combination of fat grafts and steroid local application significantly improved straight leg raising.
Percentage of patients got better

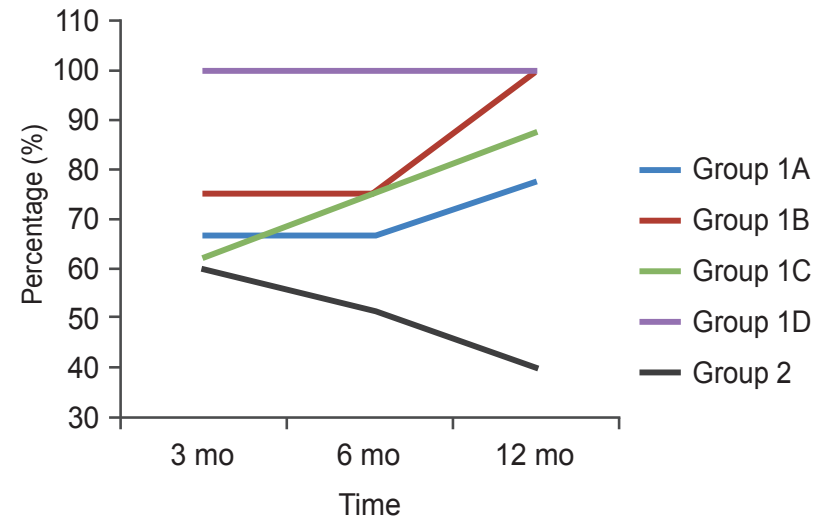

Fig. 4. Functional outcome analysis in both groups. 
Table 7. Categorized straight leg raise test analysis

\begin{tabular}{|c|c|c|c|}
\hline Group & Patients got better & Patients the same & Patients got worse \\
\hline \multicolumn{4}{|c|}{ Group 1A (45 cases) } \\
\hline $6 \mathrm{mo}$ & $30(66.7)$ & $15(33.3)$ & 0 \\
\hline $12 \mathrm{mo}$ & $30(66.7)$ & $15(33.3)$ & 0 \\
\hline $3 \mathrm{yr}$ & $35(77.8)$ & $10(22.2)$ & 0 \\
\hline \multicolumn{4}{|c|}{ Group 1B (40 cases) } \\
\hline $6 \mathrm{mo}$ & $30(75)$ & $10(25)$ & 0 \\
\hline $12 \mathrm{mo}$ & $30(75)$ & $10(25)$ & 0 \\
\hline $3 \mathrm{yr}$ & $40(100)$ & 0 & 0 \\
\hline \multicolumn{4}{|c|}{ Group 1C (40 cases) } \\
\hline 6 mo & $25(62.5)$ & $15(37.5)$ & 0 \\
\hline $12 \mathrm{mo}$ & $30(75)$ & $10(25)$ & 0 \\
\hline $3 y r$ & $35(87.5)$ & $5(12.5)$ & 0 \\
\hline \multicolumn{4}{|c|}{ Group 1D (40 cases) } \\
\hline $6 \mathrm{mo}$ & $40(100)$ & 0 & 0 \\
\hline $12 \mathrm{mo}$ & $40(100)$ & 0 & 0 \\
\hline $3 \mathrm{yr}$ & $40(100)$ & 0 & 0 \\
\hline \multicolumn{4}{|c|}{ Group 1 (total) (165 cases) } \\
\hline $6 \mathrm{mo}$ & $125(75.8)$ & $40(24.2)$ & 0 \\
\hline $12 \mathrm{mo}$ & $130(78.8)$ & $35(21.2)$ & 0 \\
\hline $3 \mathrm{yr}$ & 140 (90.9) & $15(9.1)$ & 0 \\
\hline \multicolumn{4}{|c|}{ Group 2 (125 cases) } \\
\hline $3 \mathrm{mo}$ & $75(60)$ & $50(40)$ & 0 \\
\hline $6 \mathrm{mo}$ & $65(52)$ & $50(40)$ & $10(8)$ \\
\hline $12 \mathrm{mo}$ & $50(40)$ & $55(44)$ & $20(16)$ \\
\hline
\end{tabular}

Values are presented as number (\%).

\section{Fourth: MRI findings in 12 months}

Regarding the clinical outcome analysis in relation to MRI findings at 1-year follow-up, as shown in Table 8, there was a trend toward better outcome in the intervention group. Efficacy parameters included measuring the number of sites free of EF and reduction in the severity of EF.

Fig. 7 shows that group $100 \%$ of patients in group 1D, $87 \%$ of patients in group $1 \mathrm{~B}, 75 \%$ of patients in group $1 \mathrm{C}$, and $67 \%$ of patients in group $1 \mathrm{~A}$ did not suffer from EF. However, only $36 \%$ of patients group 2 did not suffer from EF.

Fig. 8 demonstrates a control male patient 35 year's old, with history of L4-5 left posterolateral disc herniation treated surgically by spinolaminectomy at L4-5 level. The
MRI study done after 1 year (Fig. 8A) were axial consequent MRI images T1-eighted before contrast showing a ventral and left ventrolateral low signal intensity, involving the left upper outer quadrant and encroaching upon the left L4-5 neural exit foramen. After gadolinium-diethylenetriaminepentacetate (Gd-DTPA) (Fig. 8B), there was an enhancing epidural scarring involving the mentioned quadrant (grade: mild to moderate scar).

The combination of suction drainage, fat, and steroid was most effective and resulted in no EF. In addition, these findings demonstrated that fat/steroid combination provided small additional benefit as compared to those obtained by fat alone.

Fig. 9 demonstrates a female patient 27 years, who was treated surgically by spinolaminectomy with an introduction of an epidural fat (Fig. 9A) and SD; MRI images (Fig. 


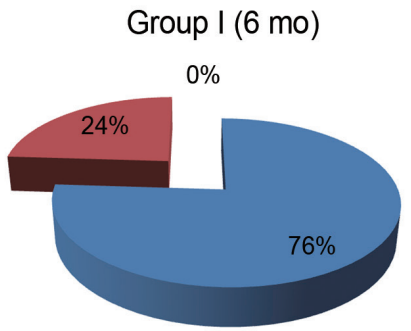

Group II (6 mo)

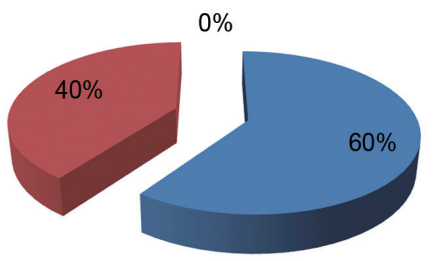

Group I (12 mo)

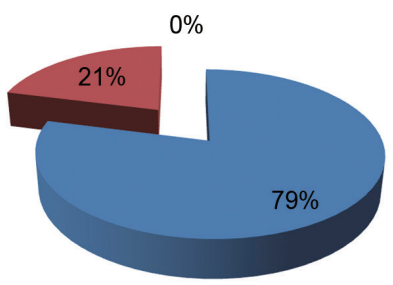

Group II (12 mo)
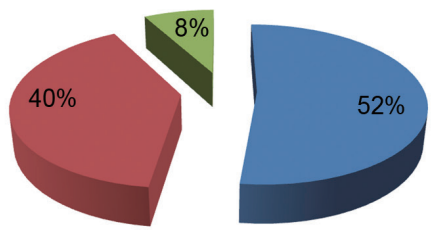

Group I (3 yr)

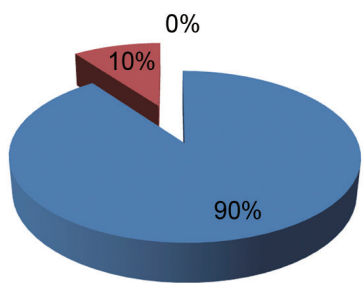

Group II (3 yr)

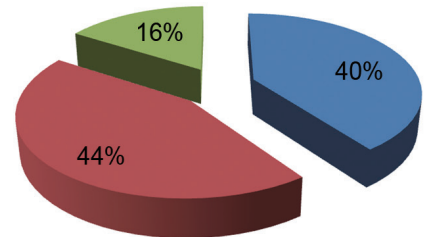

Patients got better

Patients the same

Patients got worse

Fig. 5. Percentages of Patients got better with respect to straight leg raise test in both groups.
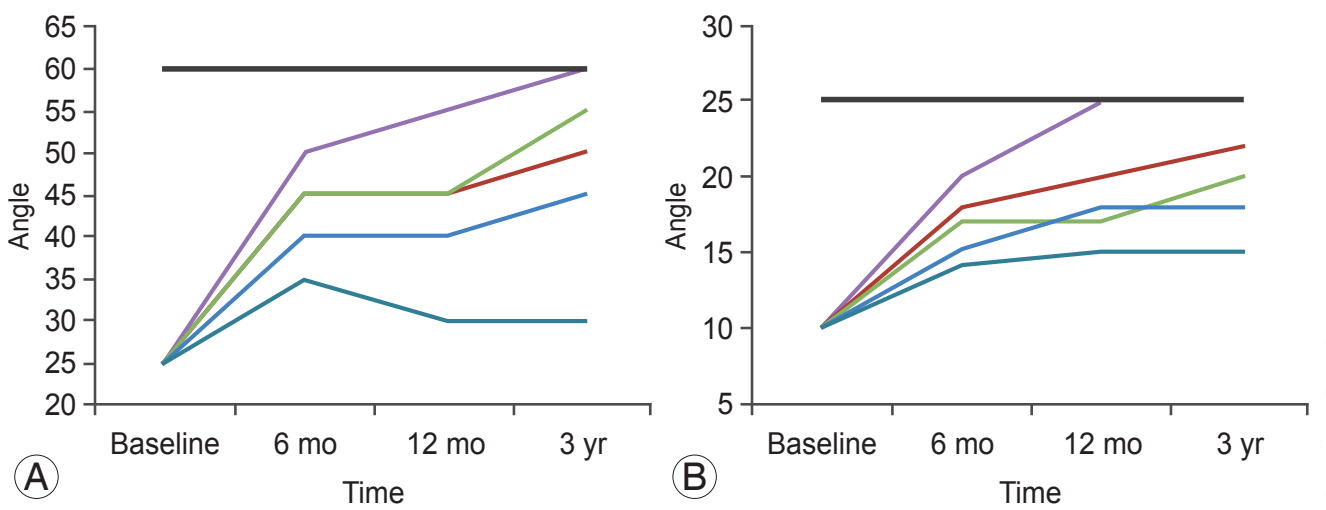

- Group 1A

- Group 1B

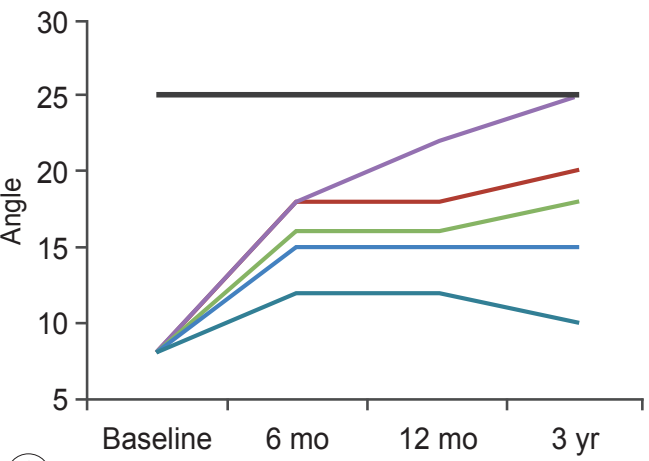

(C)

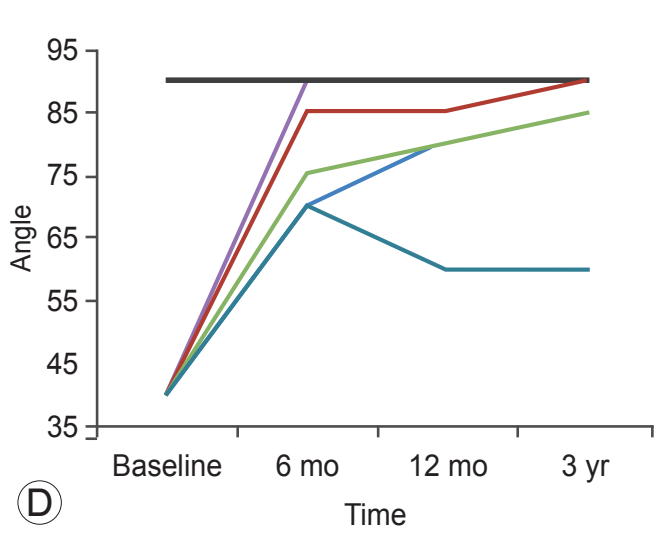

- Group 1C

- Group 1D

- Group 2

- Normal

Fig. 6. Percentages of patients got better with respect to straight leg raise (SLR) test in all groups. (A) Time series for flexion among both groups. (B) Time series for extension among both groups. (C) Time series for lateral flexion among both groups. (D) Time series for SLR test among both groups.

9B, C) at the level of spinolaminectomy one-year followup showed no evidence of abnormal signal intensity nor enhancing epidural scar.
Conclusion (6): With respect to EF, the MRI findings showed the best results in group $1 \mathrm{D}$, followed by group $1 \mathrm{~B}$, group $1 \mathrm{C}$, and group $1 \mathrm{~A}$ respectively. The worst re- 
Table 8. Clinical outcome analysis in relation to magnetic resonance imaging findings at 12 months (in mean values)

\begin{tabular}{lcccccc} 
Epidural fibrosis & \multicolumn{3}{c}{ Group I (treatment group) } & & Group II \\
(per group) & $1 \mathrm{~A}$ & $1 \mathrm{~B}$ & $1 \mathrm{C}$ & $1 \mathrm{D}$ & Total & (control) \\
\cline { 2 - 6 } Mild & $5(11.1)$ & $5(12.5)$ & $5(12.5)$ & 0 & $15 / 165(9.1)$ & $15 / 125(12)$ \\
Moderate & $10(22.2)$ & 0 & $5(12.5)$ & 0 & $15 / 165(9.1)$ & $15 / 125(12)$ \\
\hline Extensive & 0 & 0 & 0 & 0 & $0 / 165(0)$ & $50 / 125(40)$ \\
Total & $15(33.3)$ & $5(12.5)$ & $10(25)$ & 0 & $30 / 165(18.2)$ & $80 / 125(64)$ \\
\hline
\end{tabular}

Values are presented as number (\%).

Group 1A

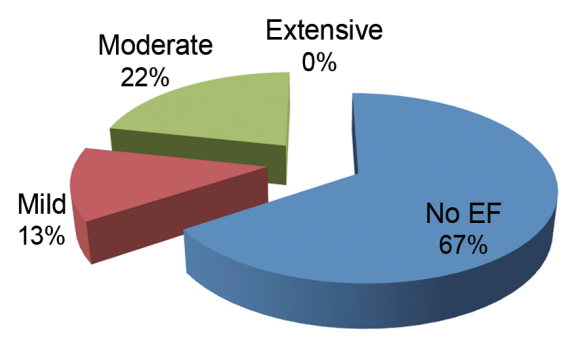

Group 1C

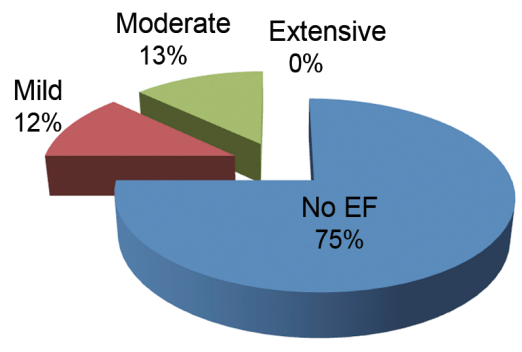

Group 1B

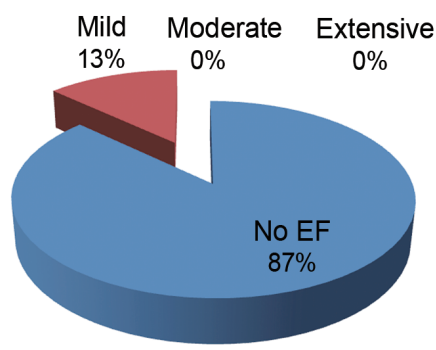

Group 1D
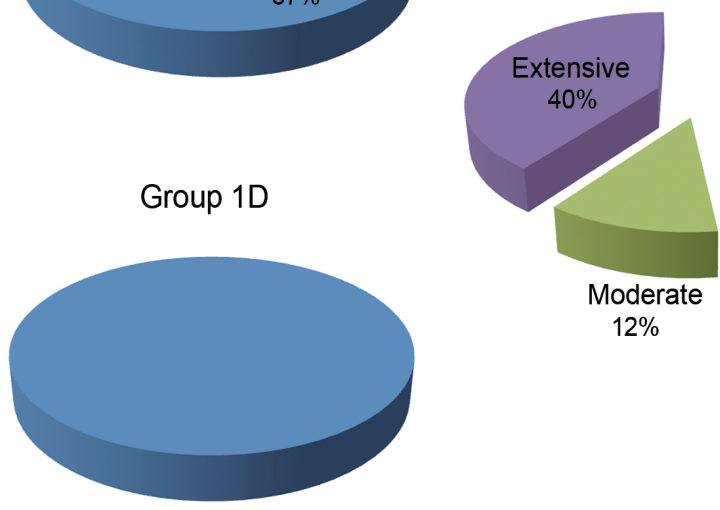

Moderate

$12 \%$
Group 2

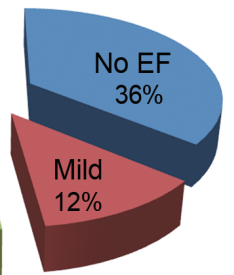

Fig. 7. Percentage of patients suffering epidural fibrosis (EF) after 1 year of surgery based on magnetic resonance imaging results.
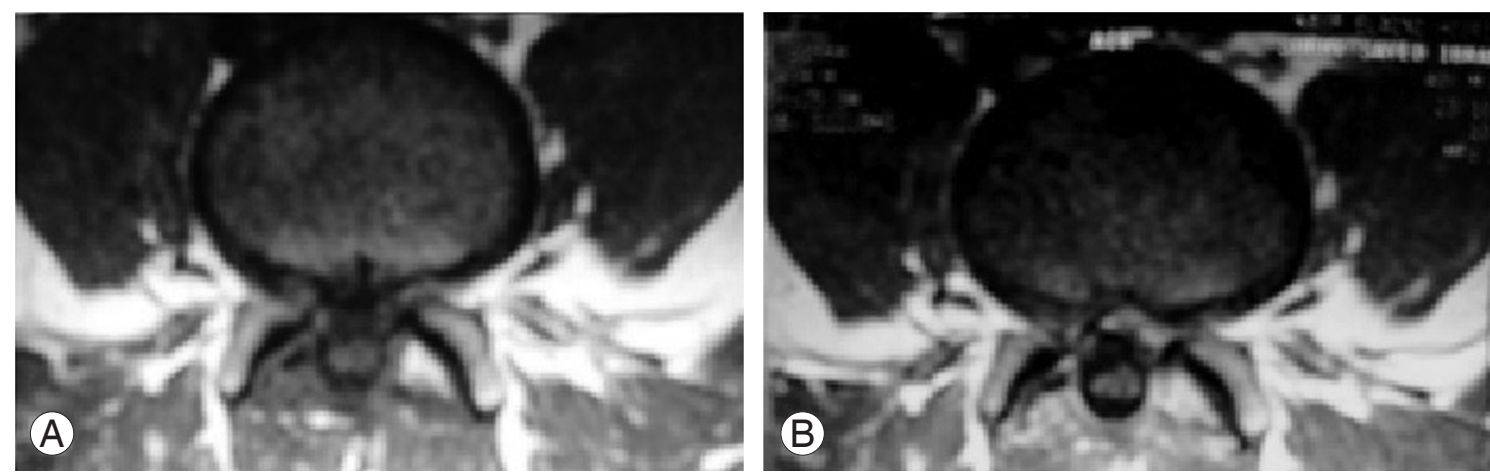

Fig. 8. Control patient 35 year's old, male, with history of $L 4-5$ left posterolateral disc herniation treated surgically by spinolaminectomy at L4-5 level. Magnetic resonance imaging (MRI) study done after 1 year (A) are axial consequent MRI images T1weighted before contrast showing a ventral and left ventrolateral low signal intensity, involving the left upper outer quadrant and encroaching upon the left L4-5 neural exit foramen. After gadolinium with DTPA (diethylenetriaminepentacetate) (B), there is an enhancing epidural scarring involving the mentioned quadrant (grade: mild to moderate $\mathrm{EF}$ ). EF, epidural fibrosis. 

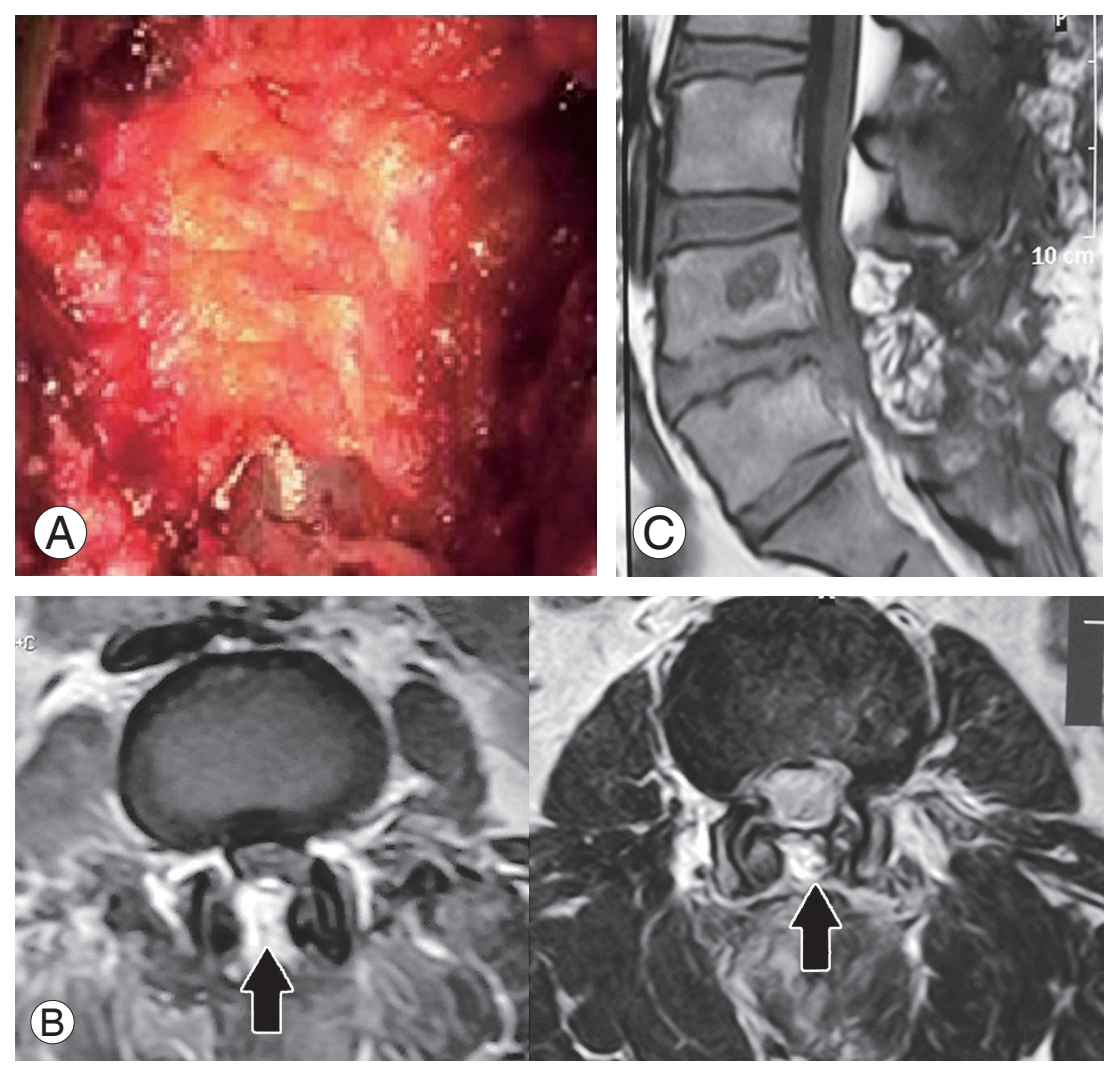

Fig. 9. Female patient 27 years, who was treated surgically by spinolaminectomy with introduction of an epidural fat $(\mathbf{A})$ and suction drains, magnetic resonance images $(\mathbf{B}, \mathbf{C})$ at the level of spinolaminectomy one year follow-up showed no evidence of abnormal signal intensity nor enhancing EF. Notice the epidural fat in place (arrows). EF, epidural fibrosis.

sults were obtained in the group 2. Therefore, it could be concluded that: using suction drainage with a combination of fat grafts and steroid local application significantly reduced the frequency and the extent of EF.

Summing up, based on the six pervious conclusion, it could be ventured that the use of suction drainage alone or combined with only fat grafts, fats grafts and local steroids application, or only local steroids application significantly improved patient outcome with respect to short-term and late pain relief, functional outcome, and SLR. In addition, the same tools significantly reduced EF as measured by an MRI.

\section{Discussion}

EF prevention has been a subject of concern for decades. In the early 1900s, Lexer [9] first reported the use of free fat grafts for prevention of scar formation. In 1948, Key and Ford [10], described scar-entrapped nerve root after lumbar surgery. In 1974, LaRocca and Macnab [2] described $\mathrm{EF}$ as the "post laminectomy membrane" in a canine model. In 1980, Mayfield [11] documented that fat grafts could prevent "constricting cicatrix", as he described. He also noted the possibility of fat grafts acting as a space occupying lesion and causing neural compression. Lumbar EF around the dura and nerve roots at and near the operative sites proved to be an important cause of FBS, which is reported to occur in $15 \%$, up to $60 \%$, of operated cases [12-19]. Of these FBS cases, EF was reported to be the cause in $10 \%$ to $24 \%$ of these cases. The postoperative recurrence of pain after an initial pain-free period was often related to EF [17]. In reoperation, the rate of EF significantly increased to even more than $60 \%$ with a consequent worse outcome [14,20]. The fibrosisentrapped nerve root is more susceptible to compression due to the tethering effect of the scar tissue around. Moreover, the presence of EF renders reoperations risky and more difficult. EF increases the risk of dural tear during reoperation [21]. Reoperation in these cases often leads to a poor outcome and further scarring [22]. We do not 
recommend reoperation when $\mathrm{EF}$ is the only cause of FBS [23].

If we consider postoperative lumbar EF occurring as a result of normal wound healing, when the operative bed hematoma is invaded by fibrous tissue from the surrounding tissues, it could then be a preventable disease $[16,24]$. LaRocca and Macnab [2] postulated that fibroblasts, of traumatized muscle origin, infiltrate and replace the epidural hematoma with granulation tissue formation. Granulation tissue then matures into a dense fibrous tissue resulting in dura and nerve root irritation, entrapment, compression, and tethering and being more susceptible to injury $[19,25]$. This results ends with recurrent disc pains and acceleration of osteophyte formation [15].

Smaller incisions, less muscle trauma, and good hemostasis failed to completely solve the problem. Even in minimally invasive procedures, EF still formed [25]. Most synthetic materials that were studied as barriers were not effective, with unsatisfactory results and actually inviting more scarring and more complications compared with control groups. Autogenous barriers had better results, including fascia lata graft, pedicled grafts, and free fat grafts $[5,6,8,18,19,23,24,26,27]$.

To minimize the risk of development of EF, we had to decrease the chance of its formation. Theoretically speaking, the absence of blood in the epidural area postoperatively reduces the possibility of EF formation. Also, preservation of the natural epidural fat is a safe and effective barrier to reduce the occurrence of EF, preventing the invasion of fibrous tissue from the surrounding tissues. So, SD for removal postoperative collections may have an important role. Moreover, providing a natural barrier between the dura and the healing tissues may also play an important role. Lastly, applying a drug locally, which is supposed to decrease scar tissue formation, may be theoretically accepted, provided that it will not add any harm to the patient.

Regarding EF and clinical recovery, Jinkins et al. [1] suggested that fibrosis in the epidural space may be less important, and Coskun et al. [13] did not find a relation between EF and pain scores. However, we have found a good correlation between scores for the NVR scale and the grade of EF by MRI. We think that the SD prevents or minimizes postoperative collections, hematoma, or seroma that give rise to EF. In our study, a significant proportion of patients in group I with SD showed pain relief compared to the control group, as well as compared to the baseline findings. Using suction drainage with a combination of fat grafts and steroid local application significantly reduced the frequency and the extent of EF, with a statistically significant difference in short-term and late pain relief between the Intervention group and control group.

Based on our findings, we suggested that fibrosis in the epidural space was important in the pathogenesis of FBS. The good correlation between EF, the MRI findings, and clinical outcomes concluded that using the studied preventive tools significantly reduced the frequency and the extent of EF. This suggested that the EF was not just a radiological entity. Many outcome scales were used to figure out the results of lumbar surgery, making it difficult to compare different studies. Complete or partial relief of pain was achieved in $56 \%$ to $86 \%$ of the reported series, long-term good to excellent results ranged from $64 \%$ to $69 \%$. We achieved clinical and neurological excellent improvement in $63.6 \%$ of our patients plus $18.2 \%$ of the cases showed fair improvement. We evaluated pain relief, and, most particularly, we evaluated activity-related pain, which is, after all, the most important thing to the patient.

The SD group at 3, 6, and 12 months was clearly superior to the control group. There was a statistically significant difference in short-term and late pain relief between the Intervention group and control group. There was a clear improvement in activity-related pain in SD patients. In the long run, using suction drainage with a combination of fat grafts and steroid local application significantly increased pain relief, significantly improved straight leg raising, and significantly enhanced functional outcome measured by flexion, extension, and lateral flexion angles. We can therefore say that SD and fat graft provide benefits, not only to the patient, but also to the surgeon.

EF formation takes about 6 weeks to 6 months postoperatively, clearly identified on MRI by at least 3 months, stabilized by 6 months, with no further changes at 12 months $[1,28,29]$. So, in this study, the MRI evaluation follow-up time was 12 months, selected for the effectiveness of analysis. With MRI, EF was clearly identified as a relatively low signal intensity, as compared with the high signal intensity epidural fat, and as the very low signal intensity cerebrospinal fluid on T1-weighted images. EF usually homogeneously enhanced the following contrast administration. So, its identification is possible and makes the differentiation of EF and disc herniation easy [29-31].

In this study, we achieved a relatively simple approach for evaluation of EF using axial MR images, with inter- 
pretation of its extent. This approach made it possible to study the relation between the extent of EF, patient's symptoms, and surgical outcomes. Precise description of the extent of EF on MRI added clear facts about the causes and pathogenesis of FBS. In contrast to the grading system described by Ross et al. [31], utilizing five levels of the vertebral body and disc level, we only utilized, in this study, three levels evaluation, centered on the level of the neural exit foramina and it was more than enough. The protocol that we used was designed to be easily followed by others.

Cervellini et al. [28], was the first to describe the rate and grade of EF. Cervellini et al. [28] and Sen et al. [6] reported seeing mostly grade II (moderate) EF. Cinotti et al. [29] did not find any correlation between the amount of EF, as seen intraoperatively and on MR, and FBS. In this study, we have evaluated the occurrence rate and EF grades in our patients. At 12 months, $82.2 \%$ of the original 290 total cases had a degree or another of EF, with $0 \%$ of the intervention group had extensive EF scores, while $40 \%$ of the control group had extensive EF scores. We observed that, in patients with SD, formation of EF was prevented or tended to be less extensive, reporting mild and moderate EF in SD-patients and extensive EF in non-SD-patients. This finding supported the idea that the presence of barrier between dura and blood prevented formation of EF. We found that both SD and fat/steroid combinations consistently reduced the frequency and the extent of EF. Combinations were most effective and resulted in up to $100 \%$ with minimal or no $\mathrm{EF}$ whereas controls exhibited over $64 \%$ of the sites with EF. Our results in patients without SD were similar to those in Cervellini's and Sen's series in that the intervention group had less extensive EF and that the control patients had a less degree of nonextensive EF. In addition, our findings demonstrated that fat/steroid combination provided small but apparent additional benefit to those obtained by fat alone, in the SD group. The SD with fat graft and local steroid application patients conversely had not a higher degree of non-extensive scar only, but a trend toward scar prevention.

Ross [30] found that patients with extensive EF were 3.2-fold more likely to experience recurrent radicular pain than those patients with less extensive EF. They reported a significant association between the presence of extensive $\mathrm{EF}$ and the recurrence of radicular pain. Our results concerning this correlation conflicted with Cinotti et al. [29] and agreed with the others [22,30,31]. This study demonstrated that, following lumbar disc surgery, with the use of $\mathrm{SD}$, fat grafts, and/or steroids, a significant proportion of patients expected to have chronic, refractory low back and lower extremity pain as part of FBS experienced improvements in NVR scores, compared to the control group. Associated improvements in functional outcomes (range of motion, and SLR tests) were also noted as compared to baseline measurements and results of the control group. Analysis of these results suggested that SD, fat grafts, and/ or steroids used after decompressive surgery significantly improved both short and long term outcomes. We considered the amount of EF seen on follow up MRI after lumbar disc surgery an important prognostic factor that should not be bypassed.

\section{Conclusions}

This study has clearly demonstrated the fact that the use of suction drainage alone or combined with only fat grafts, fats grafts and local steroids application, or only local steroids application significantly improved patient outcome with respect to short-term and late pain relief, functional outcome, and SLR. In addition, the same tools significantly reduced EF as measured by an MRI. Grading of EF with the mentioned simple MRI grading system showed a good clinical correlation between outcome on one side and the extent of EF on the other side.

\section{Conflict of Interest}

No potential conflict of interest relevant to this article was reported.

\section{References}

1. Jinkins JR, Osborn AG, Garrett D Jr, Hunt S, Story JL. Spinal nerve enhancement with Gd-DTPA: MR correlation with the postoperative lumbosacral spine. AJNR Am J Neuroradiol 1993;14:383-94.

2. LaRocca H, Macnab I. The laminectomy membrane. Studies in its evolution, characteristics, effects and prophylaxis in dogs. J Bone Joint Surg Br 1974;56: 545-50.

3. Park YK, Kim JH, Chung HS. Outcome analysis of patients after ligament-sparing microdiscectomy for lumbar disc herniation. Neurosurg Focus 2002;13:E4. 
4. Eichholz KM, Ryken TC. Complications of revision spinal surgery. Neurosurg Focus 2003;15:E1.

5. Rodgers KE, Robertson JT, Espinoza T, et al. Reduction of epidural fibrosis in lumbar surgery with Oxiplex adhesion barriers of carboxymethylcellulose and polyethylene oxide. Spine J 2003;3:277-83.

6. Sen O, Kizilkilic O, Aydin MV, et al. The role of closed-suction drainage in preventing epidural fibrosis and its correlation with a new grading system of epidural fibrosis on the basis of MRI. Eur Spine J 2005;14:409-14.

7. Anderson SR, Racz GB, Heavner J. Evolution of epidural lysis of adhesions. Pain Physician 2000;3:26270 .

8. Manchikanti L, Rivera JJ, Pampati V, et al. One day lumbar epidural adhesiolysis and hypertonic saline neurolysis in treatment of chronic low back pain: a randomized, double-blind trial. Pain Physician 2004; 7:177-86.

9. Lexer E. Neue deutsche chirurgie. In: Lexer E, editor. Die freien transplantationen. Stuttgart: Enke; 1919. p.264-545.

10. Key JA, Ford LT. Experimental intervertebral-disc lesions. J Bone Joint Surg Am 1948;30:621-30.

11. Mayfield FH. Autologous fat transplants for the protection and repair of the spinal dura. Clin Neurosurg 1980;27:349-61.

12. Annertz M, Jonsson B, Stromqvist B, Holtas S. No relationship between epidural fibrosis and sciatica in the lumbar postdiscectomy syndrome: a study with contrast-enhanced magnetic resonance imaging in symptomatic and asymptomatic patients. Spine (Phila Pa 1976) 1995;20:449-53.

13. Coskun E, Suzer T, Topuz O, Zencir M, Pakdemirli E, Tahta K. Relationships between epidural fibrosis, pain, disability, and psychological factors after lumbar disc surgery. Eur Spine J 2000;9:218-23.

14. Fritsch EW, Heisel J, Rupp S. The failed back surgery syndrome: reasons, intraoperative findings, and longterm results: a report of 182 operative treatments. Spine (Phila Pa 1976) 1996;21:626-33.

15. Gabriel EM, Friedman AH. The failed back surgery syndrome. In: Wilkins RH, Rengachary SS, editors. Neurosurgery. New York: McGraw-Hill, Health Professions Division; 1996. p.3863-70.

16. Long DM. Failed back surgery syndrome. Neurosurg Clin N Am 1991;2:899-919.
17. Maroon JC, Abla A, Bost J. Association between peridural scar and persistent low back pain after lumbar discectomy. Neurol Res 1999;21 Suppl 1:S43-6.

18. Songer MN, Ghosh L, Spencer DL. Effects of sodium hyaluronate on peridural fibrosis after lumbar laminotomy and discectomy. Spine (Phila Pa 1976) 1990;15:550-4.

19. Songer MN, Rauschning W, Carson EW, Pandit SM. Analysis of peridural scar formation and its prevention after lumbar laminotomy and discectomy in dogs. Spine (Phila Pa 1976) 1995;20:571-80.

20. Jonsson B, Stromqvist B. Repeat decompression of lumbar nerve roots: a prospective two-year evaluation. J Bone Joint Surg Br 1993;75:894-7.

21. Kim SS, Michelsen CB. Revision surgery for failed back surgery syndrome. Spine (Phila Pa 1976) 1992; 17:957-60.

22. North RB, Campbell JN, James CS, et al. Failed back surgery syndrome: 5-year follow-up in 102 patients undergoing repeated operation. Neurosurgery 1991; 28:685-90.

23. Porchet F, Lombardi D, de Preux J, Pople IK. Inhibition of epidural fibrosis with ADCON-L: effect on clinical outcome one year following re-operation for recurrent lumbar radiculopathy. Neurol Res 1999;21 Suppl 1:S51-60.

24. Llado A, Sologaistua E, Guimera J, Marin M. Expanded polytetrafluoroethylene membrane for the prevention of peridural fibrosis after spinal surgery: a clinical study. Eur Spine J 1999;8:144-50.

25. Dogulu F, Kurt G, Emmez H, et al. Topical mitomycin C-induced inhibition of postlaminectomy peridural fibrosis in rabbits. J Neurosurg 2003;99:76-9.

26. Aydin Y, Ziyal IM, Duman H, Turkmen CS, Basak M, Sahin Y. Clinical and radiological results of lumbar microdiskectomy technique with preserving of ligamentum flavum comparing to the standard microdiskectomy technique. Surg Neurol 2002;57:5-13.

27. Dullerud R, Graver V, Haakonsen M, Haaland AK, Loeb M, Magnaes B. Influence of fibrinolytic factors on scar formation after lumbar discectomy: a magnetic resonance imaging follow-up study with clinical correlation performed 7 years after surgery. Spine (Phila Pa 1976) 1998;23:1464-9.

28. Cervellini P, Curri D, Volpin L, Bernardi L, Pinna V, Benedetti A. Computed tomography of epidural fibrosis after discectomy: a comparison between symp- 
tomatic and asymptomatic patients. Neurosurgery 1988;23:710-3.

29. Cinotti G, Roysam GS, Eisenstein SM, Postacchini F. Ipsilateral recurrent lumbar disc herniation: a prospective, controlled study. J Bone Joint Surg Br 1998;80:825-32.

30. Ross JS. Magnetic resonance assessment of the post- operative spine: degenerative disc disease. Radiol Clin North Am 1991;29:793-808.

31. Ross JS, Obuchowski N, Modic MT. MR evaluation of epidural fibrosis: proposed grading system with intra- and inter-observer variability. Neurol Res 1999; 21 Suppl 1:S23-6. 